Article

\title{
Surface Free Energy Utilization to Evaluate Wettability of Hydrocolloid Suspension on Different Vegetable Epicarps
}

\author{
Fernando Osorio ${ }^{1, *}$, Gonzalo Valdés ${ }^{1}$, Olivier Skurtys ${ }^{2}$, Ricardo Andrade ${ }^{3}$, \\ Ricardo Villalobos-Carvajal ${ }^{4}$, Andrea Silva-Weiss ${ }^{1}$, Wladimir Silva-Vera ${ }^{1}$, Begoña Giménez ${ }^{1}$, \\ Marcela Zamorano ${ }^{1}$ and Johana Lopez ${ }^{1}$ \\ 1 Department of Food Science and Technology, Universidad de Santiago de Chile, Santiago 9160000, Chile; \\ gonzalo.valdesm@usach.cl (G.V.); andrea.silva@usach.cl (A.S.-W.); wladimir.silvav@usach.cl (W.S.-V.); \\ bego.gimenez@usach.cl (B.G.); marcela.zamorano@usach.cl (M.Z.); johana.lopez@usach.cl (J.L.) \\ 2 Department of Mechanical Engineering, Universidad Federico Santa María, Santiago 8940000, Chile; \\ olivier.skurtys@usm.cl \\ 3 Department of Food Engineering, Universidad de Córdoba, Montería 230002, Colombia; \\ andradepizarro@gmail.com \\ 4 Department of Food Engineering, Universidad del Bío-Bío, Chillán 3800708, Chile; r.villalobos@ubiobio.cl \\ * Correspondence: fernando.osorio@usach.cl; Tel.: +56-2-27180550
}

Academic Editor: Isabel Coelhoso

Received: 26 September 2017; Accepted: 21 December 2017; Published: 30 December 2017

\begin{abstract}
Surface free energy is an essential physicochemical property of a solid and it greatly influences the interactions between vegetable epicarps and coating suspensions. Wettability is the property of a solid surface to reduce the surface tension of a liquid in contact with it such that it spreads over the surface and wets it, resulting from intermolecular interactions when the two are brought together. The degree of wetting (wettability) is determined by an energy balance between adhesive and cohesive work. The spreading coefficient $\left(S_{\mathrm{cf} / \text { food }}\right)$ is the difference between the work of adhesion and the work of cohesion. Surface wettability is measured by the contact angle, which is formed when a droplet of a liquid is placed on a surface. The objective of this work was to determine the effect of hydroxypropyl methylcellulose (HPMC), $\mathrm{k}$-carrageenan, glycerol, and cellulose nanofiber (CNF) concentrations on the wettability of edible coatings on banana and eggplant epicarps. Coating suspension wettability on both epicarps were evaluated by contact angle measurements. For the $\left(S_{\mathrm{cf} / \mathrm{food}}\right)$ values obtained, it can be concluded that the surfaces were partially wet by the suspensions. $S_{\mathrm{cf} / \text { food }}$ on banana surface was influenced mainly by k-carrageenan concentration, HPMC-glycerol, $\mathrm{K}$-carrageenan-CNF, and glycerol-CNF interactions. Thus, increasing $\mathrm{k}$-carrageenan concentrations within the working range led to a $17.7 \%$ decrease in $S_{\text {cf/banana }}$ values. Furthermore, a HPMC concentration of $3 \mathrm{~g} / 100 \mathrm{~g}$ produced a $10.4 \%$ increase of the $S_{\mathrm{cf} / \text { banana }}$ values. Finally, $S_{\mathrm{cf} / \text { fruit }}$ values for banana epicarps were higher $(\sim 10 \%)$ than those obtained for eggplant epicarp, indicating that suspensions wetted more the banana than the eggplant surface.
\end{abstract}

Keywords: contact angle; edible coating; epicarp; spreading coefficient; wettability

\section{Introduction}

Edible coatings help to meet many challenges related to food preservation. They contribute to the extension of the shelf-life of fruits by reducing moisture and solute migration, gas exchange, respiration, and oxidative reaction rates. The functionality and performance of edible coatings depend on their mechanical, optical, and barrier properties, which in turn are related to film composition, its formation process, and the method of application on the food [1-3]. 
Edible coatings are made from biopolymer materials such as proteins (gelatin, casein, zein), polysaccharides (starch, cellulose, alginate), and lipids (beeswax, fatty acids). Cellulose derivatives such as hydroxypropyl methylcellulose (HPMC) are promising materials for edible coatings because they impart moderate strength, and they are resistant to oils and fats, as well as being flexible, transparent, odorless, tasteless, water-soluble, and moderate barriers to oxygen. However, they have poor barrier properties against water vapor transfer due to their hydrophilic nature [4-6]. Carrageenan is a generic term applied to a naturally occurring, commercially important family of hydrophilic polysaccharides extracted from a number of closely-related species of red seaweeds. Carrageenan have high molecular weight, as well as highly sulfated and linear molecules with a galactose backbone which are joined by alternating $\alpha(1 \rightarrow 3)$ and $\beta(1 \rightarrow 4)$ glycosidic linkages. $\mathrm{k}$-carrageenan displays partial solubility in cold and full solubility in hot water. The most frequently used strategies to enhance barrier properties are the use of composites and multilayered films containing a high barrier film; however, both techniques present disadvantages [7]. A recent breakthrough in composite materials is the advancement of nanotechnology. Cellulose nanofibers (CNF) are more effective than their micro-sized counterparts in reinforcing polymers as they form a percolated network connected by hydrogen bonds, provided there is a good dispersion of the nanofibers in the matrix $[8,9]$.

The coating process involves the wetting of the food surface to be coated by the coating formulation, possible penetration of the coating suspension into the peel, followed by a possible adhesion between the suspension and food surface [10]. Surface free energy is an essential physicochemical property of a solid and it greatly influences the interactions between vegetable epicarps and coating suspensions. Wettability is the ability of a solid surface to reduce the surface tension of a liquid in contact with it such that it spreads over the surface and wets it, resulting from intermolecular interactions when the two are brought together. The degree of wetting (wettability) is determined by an energy balance between adhesive and cohesive work. The spreading coefficient $\left(S_{\mathrm{cf} / \text { food }}\right)$ is the difference between the work of adhesion and the work of cohesion. Surface wettability is measured by the contact angle, which is formed when a droplet of a liquid is placed on a surface. The coating must be designed considering food surface properties (surface free energy), coating formulation properties (viscosity and surface tension), and the interfacial interaction between the food surface and coating suspension. The affinity between the food surface and coating formulation is fundamental in the coating design, considering that the effective spreading of a coating on a food is greatly influenced by the wettability of the surface by the coating formulation [11-14]. However, there are few studies in the scientific literature dealing with the study of the wettability properties of coating suspensions on food surfaces $[11,14,15]$, even though an understanding of this property represents a way to improve and develop new surface and interface interactions by modifying the liquid and/or surface properties. Contact angle as a wetting phenomenon was defined in the early 1800 s for solid, non-porous, and non-absorbent surfaces under equilibrium. The relationship for surface tension at a point of the three-phase contact line between a smooth, rigid, solid phase $\mathrm{S}$, a liquid $\mathrm{L}$, and its vapor $\mathrm{V}$ is described by the Young equation as:

$$
\gamma_{\mathrm{LV}} \cdot \cos \theta=\gamma_{\mathrm{SV}}-\gamma_{\mathrm{SL}}
$$

where $\gamma_{\mathrm{LV}}, \gamma_{\mathrm{SV}}$, and $\gamma_{\mathrm{SL}}$ are the surface tensions (or surface free energy, $\mathrm{mN} \cdot \mathrm{m}^{-1}$ ) of the liquid-vapor, solid-vapor, and solid-liquid interfaces, and $\theta$ is the contact angle. The angle value depends on the relative magnitude of the molecular forces acting within the liquid (cohesive) and between the liquid and the solid (adhesive), and spreading occurs when $\gamma_{\mathrm{SV}}-\gamma_{\mathrm{SL}}>\gamma_{\mathrm{LV}}$.

Three parameters must be considered to establish the appropriate concentrations of the different components in an edible coating formulation to be applied on a food surface: The spreading coefficient $\left(S_{\mathrm{cf} / \text { food }}\right)$, the work of adhesion $\left(W_{\mathrm{A}}\right)$, and the work of cohesion $\left(W_{\mathrm{C}}\right)$. The spreading coefficient of a solid by a liquid considers the balance between the $W_{\mathrm{A}}$ of the liquid on the solid and the $W_{\mathrm{C}}$ of the liquid $[14,15]$. The control of adhesion and cohesive energies is very important because the former promotes the spreading of the liquid, while the latter promotes its contraction [13]. Thus, the work of 
adhesion and spreading coefficient may be used to predict the adhesion of materials, evaluating those factors that affect film adhesion on food surface.

The objective of this work was to evaluate the influence of HPMC, k-carrageenan, glycerol, and CNF concentrations on the wettability of edible coatings on banana and eggplant epicarps.

\section{Materials and Methods}

\subsection{Materials}

Bananas and eggplants were purchased as fresh fruits from a local market (Santiago, Chile). The fruits were selected for their uniformity in ripeness, size, color, and absence of physical damage on their surface according to visual analysis. The fruits in their natural state without a cleaning step were cut in rectangular samples $(1.5 \mathrm{~cm} \times 2.5 \mathrm{~cm})$. The surface free energies $\left(\gamma_{\mathrm{SV}}\right)$ of banana and eggplant epicarps are 39.29 and $33.06 \mathrm{mN} \cdot \mathrm{m}^{-1}$, respectively [11]. HPMC (Methocel E19 Food Grade M.W. $1261.45 \mathrm{~g} \cdot \mathrm{mol}^{-1} ; \eta=19 \mathrm{cP}$ at $2 \% w / w$ and $T=20^{\circ} \mathrm{C}$ ) and $\mathrm{k}$-carrageenan (Carragel PGU 5289 Kappa I; $\sim 800 \mathrm{mPa} \cdot \mathrm{s}$ at $1.5 \% w / w$ ) were obtained from Blumos (Blumos S.A., Santiago, Chile), and glycerol (G) was purchased from Sigma (Sigma-Aldrich, Santiago, Chile). Cellulose nanofibers (20-70 nm wide ribbons) were obtained from agroindustrial residues produced by Gluconacetobacter swingsii sp., as reported by Castro et al. [16].

\subsection{Preparation of Coating Formulations}

$\mathrm{k}$-Carrageenan $(0.1-0.3 \% w / w)$ was dissolved in $2 / 3$ of distilled water at room temperature $\left(20^{\circ} \mathrm{C}\right)$ under agitation (1100-1300 RPM) for $30 \mathrm{~min}$. HPMC $(1-5 \% w / w)$ was dissolved in $1 / 3$ of distilled water by heating to $90 \pm 2{ }^{\circ} \mathrm{C}$ under agitation using a magnetic stirrer (400 RPM). Finally, both glycerol $(10-30 \% w / w)$ and $\mathrm{CNF}(1-5 \% w / w)$ were added at $40{ }^{\circ} \mathrm{C}$, and this mixture was then sonicated in a bath type sonicator (Branson Model 2210, Danbury, CT, USA) for $30 \mathrm{~min}$.

\subsection{Wettability of Coating Formulations on Banana and Eggplant Epicarps}

The wettability of the coating formulations on banana and eggplant epicarps was evaluated from contact angle (CA) measurements, based on the sessile drop method [17]. For each of the coating formulations, CA was measured at room temperature $\left(20^{\circ} \mathrm{C}\right)$ using an optical system comprised of a zoom video lens (Edmund Optics, Barrington, NJ, USA) connected to a Charge-coupled device (CCD) camera (Pulnix Inc., San Jose, CA, USA) operated via software. Contact angle was determined using ImageJ software $(1.47 \mathrm{v})$ with the plug-in Drop Shape Analysis. Small drops $(\sim 2 \mu \mathrm{L})$ were manually deposited using a precision microliter pipette on the fruit skins, and 10 measurements of both left and right drop CAs of the droplet were performed. Parameters like $S_{\mathrm{cf} / \text { food }}, W_{\mathrm{A}}$, and $W_{\mathrm{C}}$ were calculated from Equations (2)-(4), respectively:

$$
\begin{gathered}
S_{\frac{c f}{\text { food }}}=W_{\mathrm{A}}-W_{\mathrm{C}} \\
W_{\mathrm{A}}=\gamma_{\mathrm{SV}}+\gamma_{\mathrm{LV}}-\gamma_{\mathrm{SL}}=\gamma_{\mathrm{LV}} \cdot(1+\cos \theta) \\
W_{\mathrm{C}}=2 \cdot \gamma_{\mathrm{LV}}
\end{gathered}
$$

Surface tensions of the coating formulations were measured by the sessile drop method [14]. To validate the results, it was experimentally corroborated that the interfacial tension of the pure water/air system was $72.8 \pm 0.3 \mathrm{mN} \cdot \mathrm{m}^{-1}$.

\subsection{Statistical Design and Analysis}

The Box-Behnke statistical screening design was used to evaluate main effects, interaction effects, and quadratic effects of the independent variables (HPMC, $\mathrm{k}$-carrageenan, glycerol, and $\mathrm{CNF}$ concentrations) on the wettability $\left(S_{\mathrm{cf} / \text { food }}, W_{\mathrm{A}}\right.$, and $\left.W_{\mathrm{C}}\right)$ of fruits with different surface free energies (banana and eggplant). The levels of the independent variables were $1 \mathrm{~g}, 3 \mathrm{~g}$, and $5 \mathrm{~g} / 100 \mathrm{~g}$ 
for HPMC concentration; $0.1 \mathrm{~g}, 0.2 \mathrm{~g}$, and $0.3 \mathrm{~g} / 100 \mathrm{~g}$ for $\mathrm{k}$-carrageenan concentration; $10 \mathrm{~g}, 20 \mathrm{~g}$, and $30 \mathrm{~g} / 100 \mathrm{~g}$ for the glycerol concentration, and $1 \mathrm{~g}, 3 \mathrm{~g}$, and $5 \mathrm{~g} / 100 \mathrm{~g}$ for the CNF concentration.

Response surface methodology was applied to analyze the effect of independent variables on response variables $\left(W_{\mathrm{C}}, W_{\mathrm{A}}\right.$, and $\left.S_{\mathrm{cf} / \text { food }}\right)$. A second-order polynomial model (Equation (5)) was used to predict the experimental behavior [18].

$$
\hat{Y}=\beta_{0}+\sum_{i=1}^{k} \beta_{i} X_{i}+\sum_{i=1}^{k} \beta_{i i} X_{i}^{2}+\sum \sum_{i<j=1}^{k} \beta_{i j} X_{i} X_{j}
$$

where $\hat{Y}$ is the predicted value of the response; $\beta_{0}, \beta_{i}, \beta_{i i}$, and $\beta_{i j}$ are the regression coefficients for interception, linear, quadratic, and interaction effects, respectively; $k$ is the number of independent parameters ( $k=3$ in this study), and $\mathrm{X}_{i}, \mathrm{X}_{j}$ are the coded levels of the experimental conditions. Analysis of variance (ANOVA) was used to determine significant effects of HPMC, $\mathrm{k}$-carrageenan, glycerol, and cellulose nanofibers concentrations on $S_{\mathrm{cf} / \text { food }}, W_{\mathrm{A}}$, and $W_{\mathrm{C}}(95 \%$ confidence). The quality of the developed model was determined by the coefficients of determination $\left(R^{2}\right)$ and root mean square error (RMSE). This study design was analyzed using JMP software (version 9.0.1, SAS Institute, Cary, NC, USA).

\section{Results and Discussion}

Cohesion work $\left(W_{\mathrm{C}}\right)$, adhesion work $\left(W_{\mathrm{A}}\right)$, contact angle $(\mathrm{CA})$, and spreading coefficient values on banana $\left(S_{\mathrm{cf} / \text { banana }}\right)$ and eggplant $\left(S_{\mathrm{cf} / \text { eggplant }}\right)$ skins obtained for each coating formulation are shown in Table 1.

\subsection{Cohesion Work $\left(W_{C}\right)$ of Coating Formulations}

ANOVA results showed that the $W_{C}$ of the coating formulations was influenced significantly by the linear effect of HPMC concentration ( $p$-value $<0.05)$. The variation of $W_{C}$ with HPMC and glycerol concentrations is shown in Figure 1a, and variation of $W_{C}$ with HPMC and CNF concentrations is shown in Figure 1b. An increase in HPMC concentration led to a decrease in $W_{C}$ for all of the range of glycerol concentration evaluated, reaching a stable value around $110.5 \mathrm{mN} \cdot \mathrm{m}^{-1}$. It should be noted that $W_{C}$ values are dependent only on the surface tension (see Equation (4)). HPMC is a highly surface-active macromolecule and therefore surface tension of aqueous HPMC suspensions decrease as the HPMC concentration increases [19].

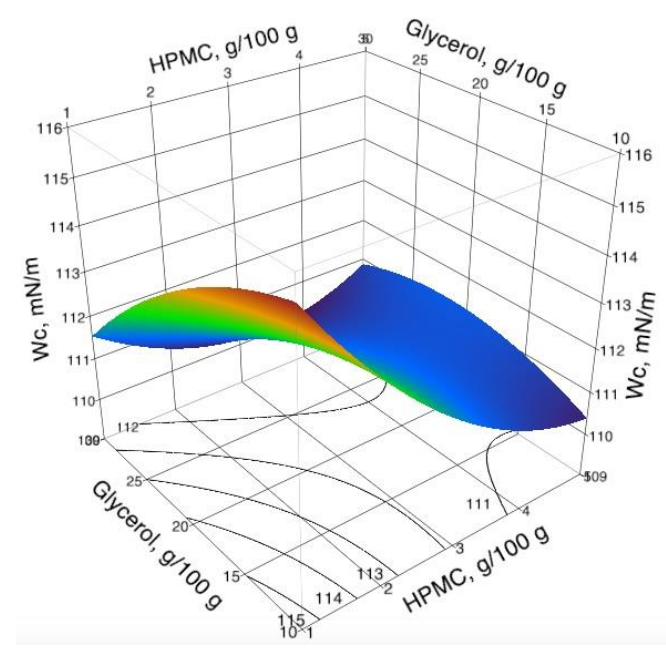

(a)

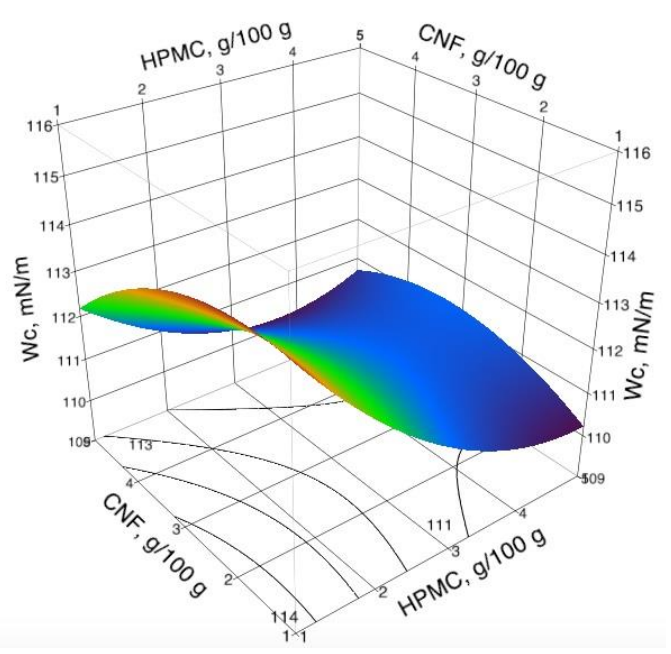

(b)

Figure 1. Response surface of $W_{C}$ as a function of (a) HPMC and glycerol, (b) HPMC and cellulose nanofibers (CNF). 
Table 1. Design matrix in the Box-Behnken model and response values obtained from experimental runs.

\begin{tabular}{|c|c|c|c|c|c|c|c|c|c|c|c|}
\hline \multirow[b]{2}{*}{ Run } & \multicolumn{4}{|c|}{ Level of Variables } & \multirow{2}{*}{$\begin{array}{l}W_{\mathrm{C}} \pm \mathrm{SD} \\
\mathrm{mN} \cdot \mathrm{m}^{-1}\end{array}$} & \multicolumn{3}{|c|}{ Banana } & \multicolumn{3}{|c|}{ Eggplant } \\
\hline & HPMC & $\mathrm{k}-\mathrm{C}^{\dagger}$ & $\mathrm{G}^{*}$ & $\mathrm{CNF}$ & & $\mathrm{CA} \pm \mathrm{SD}$ & $\begin{array}{l}W_{\mathrm{A}} \pm \mathrm{SD} \\
\mathrm{mN} \cdot \mathrm{m}^{-1}\end{array}$ & $\begin{array}{c}S_{\mathrm{cf} / \text { Banana }} \pm \mathrm{SD} \\
\mathrm{mN} \cdot \mathrm{m}^{-1}\end{array}$ & $\mathrm{CA} \pm \mathrm{SD}$ & $\begin{array}{l}W_{\mathrm{A}} \pm \mathrm{SD} \\
\mathrm{mN} \cdot \mathrm{m}^{-1}\end{array}$ & $\begin{array}{c}S_{\mathrm{cf} / \text { Eggplant }} \pm \mathrm{SD} \\
\mathrm{mN} \cdot \mathrm{m}^{-1}\end{array}$ \\
\hline S1 & 1 & 0.1 & 10 & 1 & $114.02 \pm 2.27$ & $49.0 \pm 1.7$ & $94.42 \pm 2.78$ & $-19.6 \pm 0.51$ & $61.5 \pm 1.1$ & $84.22 \pm 1.93$ & $-29.8 \pm 0.34$ \\
\hline S2 & 1 & 0.1 & 10 & 5 & $114.26 \pm 2.64$ & $65.0 \pm 0.9$ & $81.26 \pm 1.51$ & $-33.0 \pm 1.13$ & $67.2 \pm 1.7$ & $79.26 \pm 2.81$ & $-35.0 \pm 0.17$ \\
\hline S3 & 1 & 0.1 & 30 & 1 & $115.64 \pm 3.47$ & $45.4 \pm 1.6$ & $98.44 \pm 2.76$ & $-17.2 \pm 0.71$ & $59.2 \pm 1.0$ & $87.44 \pm 1.72$ & $-28.2 \pm 1.75$ \\
\hline S4 & 1 & 0.1 & 30 & 5 & $108.9 \pm 2.38$ & $39.8 \pm 1.8$ & $96.3 \pm 3.03$ & $-12.6 \pm 0.65$ & $49.8 \pm 1.3$ & $89.6 \pm 2.27$ & $-19.3 \pm 0.11$ \\
\hline S5 & 1 & 0.3 & 10 & 1 & $124.7 \pm 1.85$ & $51.9 \pm 1.6$ & $100.8 \pm 2.32$ & $-23.9 \pm 0.47$ & $48.3 \pm 0.7$ & $103.8 \pm 1.17$ & $-20.9 \pm 0.68$ \\
\hline S6 & 1 & 0.3 & 10 & 5 & $115.5 \pm 2.06$ & $53.5 \pm 0.9$ & $92.1 \pm 1.58$ & $-23.4 \pm 0.48$ & $53.4 \pm 1.8$ & $92.2 \pm 2.98$ & $-23.3 \pm 0.92$ \\
\hline S7 & 1 & 0.3 & 30 & 1 & $111.04 \pm 2.56$ & $60.8 \pm 1.5$ & $82.64 \pm 2.51$ & $-28.4 \pm 0.50$ & $59.9 \pm 1.2$ & $83.34 \pm 1.96$ & $-27.7 \pm 0.60$ \\
\hline S8 & 1 & 0.3 & 30 & 5 & $115.8 \pm 2.95$ & $49.1 \pm 1.2$ & $95.8 \pm 1.85$ & $-20.0 \pm 1.10$ & $53.9 \pm 1.3$ & $92.0 \pm 2.27$ & $-23.8 \pm 0.68$ \\
\hline S9 & 5 & 0.1 & 10 & 1 & $112.78 \pm 2.49$ & $47.0 \pm 1.8$ & $94.88 \pm 2.76$ & $-17.9 \pm 0.27$ & $61.6 \pm 1.9$ & $83.18 \pm 2.92$ & $-29.6 \pm 0.43$ \\
\hline S10 & 5 & 0.1 & 10 & 5 & $111.64 \pm 2.52$ & $50.5 \pm 1.9$ & $91.34 \pm 3.13$ & $-20.3 \pm 0.69$ & $57.7 \pm 1.8$ & $85.64 \pm 2.91$ & $-26.0 \pm 0.39$ \\
\hline S11 & 5 & 0.1 & 30 & 1 & $109.78 \pm 2.46$ & $50.1 \pm 1.1$ & $90.08 \pm 1.77$ & $-19.7 \pm 0.61$ & $59.1 \pm 1.7$ & $83.08 \pm 2.77$ & $-26.7 \pm 0.31$ \\
\hline S12 & 5 & 0.1 & 30 & 5 & $110.26 \pm 3.11$ & $57.5 \pm 1.6$ & $84.76 \pm 2.61$ & $-25.5 \pm 0.50$ & $58.0 \pm 1.4$ & $84.36 \pm 2.46$ & $-25.9 \pm 0.65$ \\
\hline S13 & 5 & 0.3 & 10 & 1 & $109.96 \pm 3.34$ & $56.7 \pm 1.7$ & $85.16 \pm 2.88$ & $-24.8 \pm 0.46$ & $64.8 \pm 1.2$ & $78.36 \pm 1.90$ & $-31.6 \pm 1.44$ \\
\hline S14 & 5 & 0.3 & 10 & 5 & $111.96 \pm 3.33$ & $57.3 \pm 1.8$ & $86.26 \pm 2.88$ & $-25.7 \pm 0.45$ & $56.6 \pm 1.7$ & $86.76 \pm 2.81$ & $-25.2 \pm 0.52$ \\
\hline S15 & 5 & 0.3 & 30 & 1 & $114.00 \pm 2.68$ & $61.4 \pm 1.7$ & $84.3 \pm 2.98$ & $-29.7 \pm 0.30$ & $61.6 \pm 1.4$ & $84.10 \pm 2.40$ & $-29.9 \pm 0.28$ \\
\hline S16 & 5 & 0.3 & 30 & 5 & $113.00 \pm 2.69$ & $53.9 \pm 1.7$ & $89.8 \pm 2.75$ & $-23.2 \pm 0.60$ & $55.3 \pm 1.4$ & $88.70 \pm 2.20$ & $-24.3 \pm 0.49$ \\
\hline S17 & 1 & 0.2 & 20 & 3 & $112.24 \pm 2.31$ & $58.0 \pm 1.6$ & $85.84 \pm 2.84$ & $-26.4 \pm 0.53$ & $59.0 \pm 1.1$ & $85.04 \pm 1.90$ & $-27.2 \pm 0.41$ \\
\hline S18 & 5 & 0.2 & 20 & 3 & $112.74 \pm 2.96$ & $66.8 \pm 1.8$ & $78.54 \pm 2.83$ & $-34.2 \pm 0.13$ & $57.3 \pm 1.5$ & $86.84 \pm 2.57$ & $-25.9 \pm 0.39$ \\
\hline S19 & 3 & 0.1 & 20 & 3 & $113.46 \pm 2.42$ & $53.8 \pm 1.7$ & $90.26 \pm 2.70$ & $-23.2 \pm 0.28$ & $50.0 \pm 1.6$ & $93.16 \pm 2.71$ & $-20.3 \pm 0.29$ \\
\hline S20 & 3 & 0.3 & 20 & 3 & $113.42 \pm 2.42$ & $58.4 \pm 1.7$ & $86.42 \pm 2.58$ & $-27.0 \pm 0.16$ & $44.8 \pm 1.1$ & $96.92 \pm 1.84$ & $-16.5 \pm 0.58$ \\
\hline S21 & 3 & 0.2 & 10 & 3 & $110.42 \pm 1.91$ & $53.5 \pm 1.8$ & $88.02 \pm 3.07$ & $-22.4 \pm 1.16$ & $64.7 \pm 0.9$ & $78.82 \pm 1.47$ & $-31.6 \pm 0.44$ \\
\hline S22 & 3 & 0.2 & 30 & 3 & $111.18 \pm 2.13$ & $51.8 \pm 1.9$ & $89.98 \pm 2.93$ & $-21.2 \pm 0.80$ & $60.5 \pm 1.2$ & $82.98 \pm 2.07$ & $-28.2 \pm 0.60$ \\
\hline S23 & 3 & 0.2 & 20 & 1 & $109.52 \pm 2.95$ & $62.5 \pm 1.7$ & $80.02 \pm 3.00$ & $-29.5 \pm 0.50$ & $69.6 \pm 1.7$ & $73.82 \pm 2.80$ & $-35.7 \pm 0.15$ \\
\hline S24 & 3 & 0.2 & 20 & 5 & $111.74 \pm 2.76$ & $62.8 \pm 1.6$ & $81.44 \pm 2.49$ & $-30.3 \pm 0.27$ & $53.5 \pm 1.4$ & $89.14 \pm 2.44$ & $-22.6 \pm 0.32$ \\
\hline S25 & 3 & 0.2 & 20 & 3 & $110.62 \pm 2.40$ & $53.9 \pm 1.6$ & $87.92 \pm 2.71$ & $-22.7 \pm 0.31$ & $55.8 \pm 1.0$ & $86.42 \pm 1.66$ & $-25.2 \pm 0.74$ \\
\hline S26 & 3 & 0.2 & 20 & 3 & $111.64 \pm 2.33$ & $54.7 \pm 1.7$ & $88.04 \pm 2.91$ & $-23.6 \pm 0.58$ & $56.2 \pm 1.4$ & $86.84 \pm 2.48$ & $-24.8 \pm 0.15$ \\
\hline S27 & 3 & 0.2 & 20 & 3 & $112.28 \pm 2.82$ & $54.5 \pm 1.6$ & $88.78 \pm 2.84$ & $-23.5 \pm 0.20$ & $56.6 \pm 1.2$ & $87.08 \pm 2.21$ & $-25.2 \pm 0.61$ \\
\hline S28 & 3 & 0.2 & 20 & 3 & $111.94 \pm 1.91$ & $54.9 \pm 1.6$ & $88.14 \pm 2.80$ & $-23.8 \pm 0.89$ & $55.5 \pm 1.2$ & $87.64 \pm 2.19$ & $-24.3 \pm 0.28$ \\
\hline S29 & 3 & 0.2 & 20 & 3 & $113.36 \pm 2.76$ & $55.4 \pm 1.7$ & $88.86 \pm 2.92$ & $-24.5 \pm 0.16$ & $56.5 \pm 1.6$ & $87.96 \pm 2.90$ & $-25.4 \pm 0.34$ \\
\hline S30 & 3 & 0.2 & 20 & 3 & $112.34 \pm 2.44$ & $54.8 \pm 1.8$ & $88.54 \pm 2.89$ & $-23.8 \pm 0.45$ & $56.9 \pm 1.0$ & $86.84 \pm 1.83$ & $-25.5 \pm 0.61$ \\
\hline S31 & 3 & 0.2 & 20 & 3 & $110.32 \pm 2.25$ & $55.2 \pm 1.4$ & $86.62 \pm 2.42$ & $-23.7 \pm 0.17$ & $55.5 \pm 1.6$ & $86.42 \pm 2.88$ & $-25.9 \pm 0.63$ \\
\hline
\end{tabular}

Notes: $\mathrm{k}-\mathrm{C}^{\dagger}$ — $^{\dagger} \mathrm{k}$-carrageenan, and $\mathrm{G}{ }^{*}{ }^{*}$ Glycerol; SD—Standard Deviation. 
To obtain a better coating, it is important to select a coating formulation with a low cohesive energy $\left(W_{\mathrm{C}}\right)$ to obtain a better adhesion between the coating suspension and the fruit epicarp. As previously mentioned, it is possible to obtain a lower $W_{C}$ when using $30 \mathrm{~g} / 100 \mathrm{~g}$ rather than $10 \mathrm{~g} / 100 \mathrm{~g}$ of glycerol. On the other hand, the application of $1 \mathrm{~g} / 100 \mathrm{~g}$ HPMC led to a reduction of $W_{C}$ values for the glycerol concentrations evaluated in this work, being noticeable for increasing glycerol concentration.

For CNF-HPMC (Figure 1b), $W_{C}$ showed a similar behavior as the glycerol-HPMC interaction, where the presence of a solute such as CNF led to an increase in $W_{C}$; this behavior agrees with the fact that the nanocellulose fibers have a high surface tension $\left(\sim 60 \mathrm{~mJ} \cdot \mathrm{m}^{-2}\right)$, and the surface is highly hydrophilic [20].

\subsection{Spreading Coefficient of Coating Formulations on Banana Epicarp}

Analysis of variance (ANOVA) showed that $S_{\text {cf/banana }}$ is influenced significantly by k-carrageenan concentration, by the interaction effect of HPMC-glycerol, $\mathrm{k}$-carrageenan-CNF, and glycerol-CNF, and by the quadratic effects of glycerol and HPMC concentrations ( $p$-values $<0.05$ ).

Figure 2 shows the surface response plot of the spreading coefficient $\left(S_{\mathrm{cf} / \mathrm{banana}}\right)$ of the coating suspensions on banana epicarp. The evolution of $S_{\text {cf/banana }}$ as a function of $k$-carrageenan-glycerol and HPMC-CNF concentrations are shown in Figure 2a,b, respectively. An increase of $k$-carrageenan concentration from the low level $(0.1 \mathrm{~g} / 100 \mathrm{~g})$ to the high level $(0.3 \mathrm{~g} / 100 \mathrm{~g})$ led to a decrease of $17.7 \%$ in $S_{\text {cf } / \text { banana }}$ values at $3 \mathrm{~g} / 100 \mathrm{~g}$ HPMC. Furthermore, the increase of glycerol concentration from the low level $(10 \mathrm{~g} / 100 \mathrm{~g})$ to the medium level $(20 \mathrm{~g} / 100 \mathrm{~g})$ produced a decrease of $28 \%$ in this parameter, which is the worst condition for wetting of this food surface. Thus, the desirable condition for a better wettability of banana surface is using a glycerol concentration of $(30 \mathrm{~g} / 100 \mathrm{~g})$ for a $\mathrm{k}$-carrageenan concentration of $0.1 \mathrm{~g} / 100 \mathrm{~g}$.

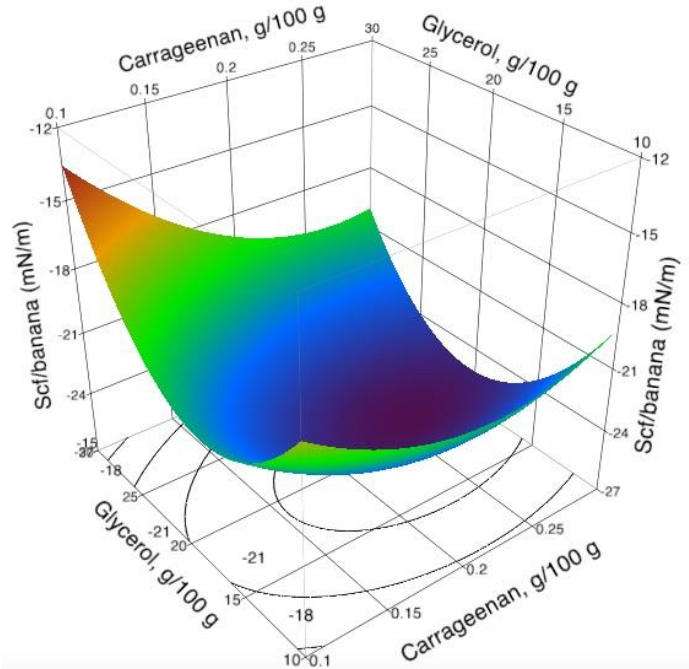

(a)

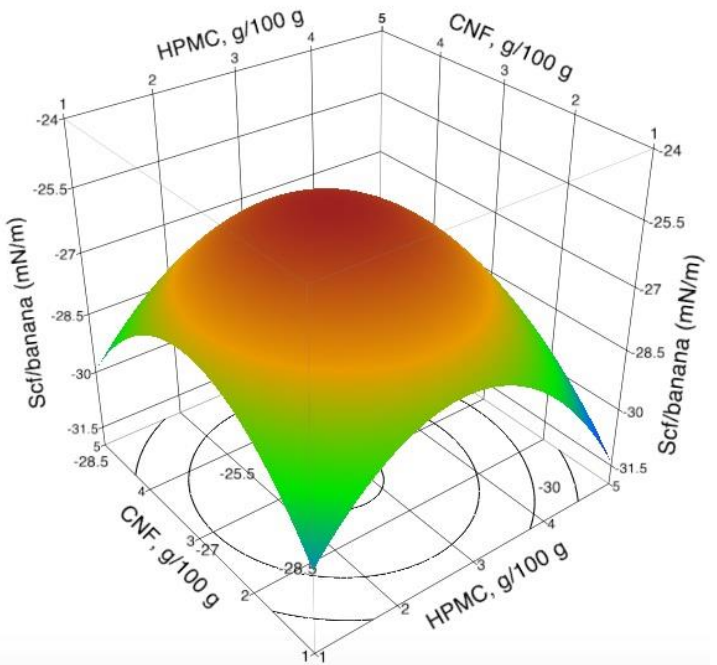

(b)

Figure 2. Response surface of $S_{\mathrm{cf} / \text { banana }}$ as a function of (a) k-carrageenan and glycerol, (b) HPMC and cellulose nanofibers (CNF).

Finally, the change of HPMC concentration from the low level $(1 \mathrm{~g} / 100 \mathrm{~g})$ to the medium level $(3 \mathrm{~g} / 100 \mathrm{~g})$ led to an increase of $10.4 \%$ in $S_{\mathrm{cf} / \text { banana }}$ values $\left(\sim-25.4 \mathrm{mN} \cdot \mathrm{m}^{-1}\right)$, and the CNF effect itself was lower than the other parameters evaluated. From the optimal analysis, the maximum of $S_{\text {cf } / \text { banana }}$ value was $-13.03 \mathrm{mN} \cdot \mathrm{m}^{-1}$ for $2.17 \mathrm{~g} / 100 \mathrm{~g}$ of HPMC, $0.10 \mathrm{~g} / 100 \mathrm{~g}$ of $\mathrm{k}$-carrageenan, $30.00 \mathrm{~g} / 100 \mathrm{~g}$ of glycerol, and $2.85 \mathrm{~g} / 100 \mathrm{~g}$ of CNF. It should be noted that the spreading coefficients obtained for HPMC coating formulations on banana epicarps in this study (ranging from -12.6 to $-34.2 \mathrm{mN} \cdot \mathrm{m}^{-1}$ ) were higher than those reported in previous studies [11] for gelatin-based coatings (ranging from 
-27.1 to $-43.9 \mathrm{mN} \cdot \mathrm{m}^{-1}$ ), which indicates that the wettability of HPMC-based coating formulations on banana epicarps was higher than that of gelatin-based coating formulations.

\subsection{Spreading Coefficient of Coating Formulations on Eggplant Epicarp}

From ANOVA analysis, the surface showed that $S_{\text {cf/eggplant }}$ is influenced significantly by CNF concentration, quadratic effects $\mathrm{k}$-carrageenan, and glycerol concentration ( $p$-values $<0.05)$.

Figure 3 shows the surface response of the spreading coefficient of the coating formulations on eggplant epicarp ( $\left.S_{\text {cf/eggplant }}\right)$ as a function of glycerol-CNF (Figure 3a) and k-carrageenan-CNF concentrations (Figure $3 \mathrm{~b})$. An increase in the CNF concentration from the low level $(1 \mathrm{~g} / 100 \mathrm{~g})$ to the high level (5 g/100 g) led to an increase of $12.5 \%$ in $S_{\text {cf/eggplant }}$ values; similarly, an increase of glycerol concentration produced an increase of $14.3 \%$ in this parameter. Thus, there is evidence of a synergic effect of CNF-glycerol at $3 \mathrm{~g} / 100 \mathrm{~g}$ and $20 \mathrm{~g} / 100 \mathrm{~g}$, respectively on $S_{\text {cf } / \text { eggplant }}$ when working at $3 \mathrm{~g} / 100 \mathrm{~g}$ of HPMC obtaining a value around $-25 \mathrm{mN} \cdot \mathrm{m}^{-1}$. However, the increase of K-carrageenan concentration from the low level $(0.1 \mathrm{~g} / 100 \mathrm{~g})$ to the medium level $(0.2 \mathrm{~g} / 100 \mathrm{~g})$ led to a decrease of $40.1 \%$ in $S_{\text {cf/eggplant }}$ at $3 \mathrm{~g} / 100 \mathrm{~g}$ of HPMC, becoming the worst condition for the wettability process. From the optimal analysis, the maximum of $S_{\mathrm{cf} / \text { eggplant }}$ was $-16.10 \mathrm{mN} \cdot \mathrm{m}^{-1}$ for $1.19 \mathrm{~g} / 100 \mathrm{~g}$ of HPMC, $0.30 \mathrm{~g} / 100 \mathrm{~g}$ of $\mathrm{K}$-carrageenan, $19.98 \mathrm{~g} / 100 \mathrm{~g}$ of glycerol, and $3.47 \mathrm{~g} / 100 \mathrm{~g}$ of CNF. The wettability of HPMC-based coating formulations on eggplant epicarps was higher than that reported in the literature [11] for gelatin-based coating formulations, where the spreading coefficients ranged from -28.8 to $-66.8 \mathrm{mN} \cdot \mathrm{m}^{-1}$.

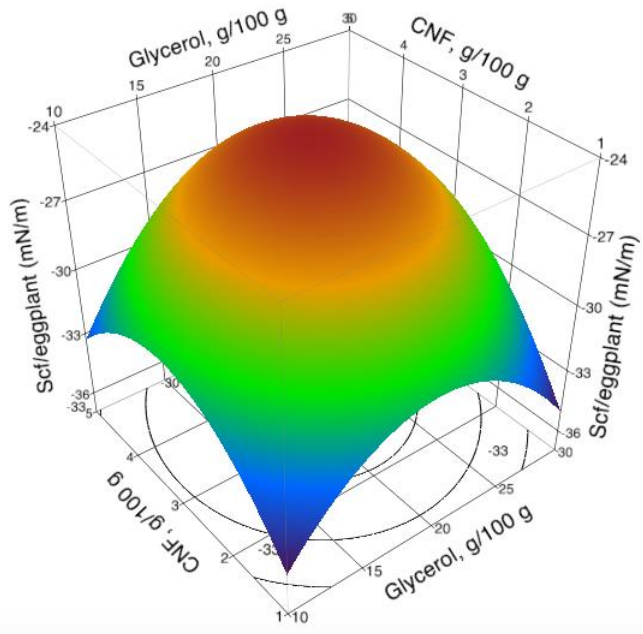

(a)

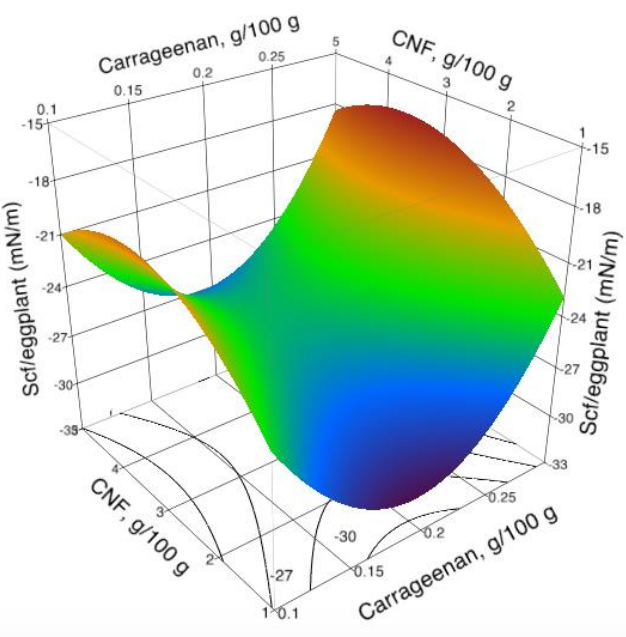

(b)

Figure 3. Response surface of $S_{\text {cf/eggplant }}$ as a function of (a) cellulose nanofibers (CNF) and glycerol, (b) $\mathrm{K}$-carrageenan and cellulose nanofibers (CNF).

An approximation was obtained from the contact angle evaluation $\left(\theta_{\text {banana }}<\theta_{\text {eggplant }}\right)$ where the banana surface facilitated the wetting; this is probably due to the chemical cuticle composition. Eggplant cuticle is composed mostly of n-alkane groups such as n-hentriacontane $\left(C_{31}\right)$ and triterpenoid alcohols ( $\alpha$-and $\beta$-amyrin) as predominant wax components [21], thus the presence of triterpenoid compounds such as ursolic acid may make the surface cuticle more difficult to wet [22], showing a tendency to form weak bonds through Van der Waals forces. Meanwhile, the banana cuticle surface is composed of ketones and aldehydes which can form hydrogen bonds [11]. Therefore, for those suspensions which present a surface tension less than the superficial free energy, there is a tendency to fully wet the surface, this may be expressed as $S_{\mathrm{cf} / \text { food }}=0$; in the case of partial wettability it may be expressed as $S_{\mathrm{cf} / \text { food }}<0[23,24]$. The results obtained are in agreement with those expected because both eggplant and banana surface tension is above the surface free energy value $\left(33.06 \mathrm{mN} \cdot \mathrm{m}^{-1}\right.$ and 
$39.29 \mathrm{mN} \cdot \mathrm{m}^{-1}$, respectively). However, the physical influence of the vegetable surface nature may be considered as another factor that influences the wettability phenomenon. Thus, the roughness presence may be considered and evaluated using surface entropy analysis [25]; also, the coating porosity could be obtained by etching and calculated as function of the mass fraction, and the coating volume fractions can be calculated using TEM [26]. Nevertheless, there are sophisticated methods for measuring texture properties associated with nature, origin, and depth of traps using $X$-ray-induced thermally stimulated currents (TSC) and thermoluminescence (TL) [27]. Other recent advances in surface inspection include computer vision and image processing techniques [28]. All mentioned techniques could be a feasible way of proving surface structure effects on wettability processes to be considered in future works.

\section{Conclusions}

It was possible to evaluate the work of cohesion and adhesion on vegetable surfaces with different free energy surfaces; coating formulations reinforced with nanofibers showed partial wettability, which was attributed to the chemical nature of the surfaces. According to statistical analysis, HPMC showed the major influence on the work of cohesion, decreasing its values with increasing HPMC concentration. In addition, in coated HPMC-based films, concentrations of glycerol, nanofibers, and k-carrageenan showed a significant influence on the work of spreading, showing both synergistic and antagonistic effects under specific formulations. Finally, values for the spreading work for high free energy surface values were higher (around 10\%) than those of low free energy values (represented by eggplant, with a free energy value of $33.06 \mathrm{mN} \cdot \mathrm{m}^{-1}$ ), which indicates that surfaces with high values of surface free energy show more affinity for these types of formulations.

Acknowledgments: The authors would like to thank the support given by Fondecyt-Chile Project 1161079; Proyectos Basales and Vicerrectoría de Investigación, Desarrollo e Innovación, Universidad de Santiago de Chile, USACH; MECESUP USA 1555 Chile; and Dicyt-Usach.

Author Contributions: Olivier Skurtys, Fernando Osorio and Ricardo Andrade conceived and designed the experiments; performed the experiments; and analyzed the data; contributed reagents/materials/analysis tools; wrote the paper. Wladimir Silva-Vera, Ricardo Villalobos-Carvajal, Andrea Silva-Weiss, Marcela Zamorano, and Johana Lopez performed the experiments; Gonzalo Valdés and Begoña Giménez analyzed the data.

Conflicts of Interest: The authors declare no conflict of interest. The founding sponsors had no role in the design of the study; in the collection, analyses, or interpretation of data; in the writing of the manuscript, and in the decision to publish the results.

\section{References}

1. Andrade, R.D.; Skurtys, O.; Osorio, F.A. Atomizing spray systems for application of edible coatings. Compr. Rev. Food Sci. Food Saf. 2012, 11, 323-337. [CrossRef]

2. Lin, D.; Zhao, Y. Innovations in the development and application of edible coatings for fresh and minimally processed fruits and vegetables. Compr. Rev. Food Sci. Food Saf. 2007, 6, 60-75. [CrossRef]

3. Liu, Y.; Wang, S.; Lan, W.; Qin, W. Fabrication and testing of PVA/Chitosan bilayer films for strawberry packaging. Coatings 2017, 7, 109. [CrossRef]

4. Gennadios, A.; McHugh, T.; Weller, C.; Krochta, J.M. Edible coatings and films based on proteins. In Edible Coatings and Films to Improve Food Quality; Krochta, J., Baldwin, E., Nisperos-Carriedo, M., Eds.; Technomic Publishing Company: Lancaster, PA, USA, 1994; pp. 201-277.

5. McHugh, T.; Senesi, E. Apple wraps: A novel method to improve the quality and extend the shelf life of fresh-cut apples. J. Food Sci. 2000, 65, 480-485. [CrossRef]

6. Fahs, A.; Brogly, M.; Bistac, S.; Schmitt, M. Hydroxypropyl methylcellulose (HPMC) formulated films: Relevance to adhesion and friction surface properties. Carbohydr. Polym. 2010, 80, 105-114. [CrossRef]

7. Arora, A.; Padua, G.W. Review: Nanocomposites in food packaging. J. Food Sci. 2010, 75, R43-R49. [CrossRef] [PubMed]

8. Azeredo, H.; Mattoso, L.; Avena-Bustillos, R.; Filho, G.; Munford, M.; Wood, D.; McHugh, T. Nanocellulose reinforced chitosan composite films as affected by nanofiller loading and plasticizer content. J. Food Sci. 2010, 75, N1-N7. [CrossRef] [PubMed] 
9. Savadekar, N.R.; Karande, V.S.; Vigneshwaran, N.; Bharimalla, A.K.; Mhaske, S.T. Preparation of nano cellulose fibers and its application in kappa-carrageenan based film. Int. J. Biol. Macromol. 2012, 51, 1008-1013. [CrossRef] [PubMed]

10. Hershko, V.; Klein, E.; Nussinovith, A. Relationships between edible coatings and garlic skin. J. Food Sci. 1996, 61, 769-777. [CrossRef]

11. Andrade, R.D.; Skurtys, O.; Osorio, F.A.; Zuluaga, R.; Gañán, P.; Castro, C. Wettability of gelatin coating formulations containing cellulose nanofibers on banana and eggplant epicarps. LWT Food Sci. Technol. 2014, 58, 158-165. [CrossRef]

12. Andrade, R.D.; Skurtys, O.; Osorio, F.A. Drop impact behavior on food using spray coating: Fundamentals and applications. Food Res. Int. 2013, 54, 397-405. [CrossRef]

13. Ribeiro, C.; Vicente, A.A.; Teixeira, J.A.; Miranda, C. Optimization of edible coating composition to retard strawberry fruit senescence. Postharvest Biol. Technol. 2007, 44, 63-70. [CrossRef]

14. Skurtys, O.; Velásquez, P.; Henriquez, O.; Matiacevich, S.; Enrione, J.; Osorio, F. Wetting behavior of chitosan solutions on blueberry epicarp with or without epicuticular waxes. LWT Food Sci. Technol. 2011, 44, 1449-1457. [CrossRef]

15. Ramírez, C.; Gallegos, I.; Ihl, M.; Bifani, V. Study of contact angle, wettability and water vapor permeability in carboxymethylcellulose (CMC) based film with murta leaves (Ugni molinae Turcz) extract. J. Food Eng. 2012, 109, 424-429. [CrossRef]

16. Castro, C.; Zuluaga, R.; Putaux, J.; Caro, G.; Mondragon, I.; Gañan, P. Structural characterization of bacterial Cellulose produced by Gluconacetobacter swingii sp. from Colombian agroindustrial wastes. Carbohydr. Polym. 2011, 84, 96-102. [CrossRef]

17. Kwok, D.Y.; Neumann, A.W. Contact angle measurement and contact angle interpretation. Adv. Colloid Interface Sci. 1999, 81, 167-249. [CrossRef]

18. Neter, J.; Wasserman, W.; Kutner, M. Applied Linear Statistical Models: Regresion, Analysis of Variance, and Experimental Design, 2nd ed.; Richard D. Irwin, Inc.: Homewood, IL, USA, 1985.

19. Avranas, A.; Tasopoulos, V. Aqueous solutions of Sodium deoxycholate and Hydroxypropylmethylcellulose: Dynamic surface tension measurements. J. Colloid Interface Sci. 2000, 221, 223-229. [CrossRef] [PubMed]

20. Abdelmouleh, M.; Boufi, S.; Belgacem, M.N.; Duarte, A.P.; Ben Salah, A.; Gandini, A. Modification of cellulosic fibers with functionalized Silanes: Development of surface properties. Int. J. Adhes. Adhes. 2004, 24, 43-54. [CrossRef]

21. Lara, I.; Belge, B.; Goulao, L.F. A focus on the biosynthesis and composition of cuticle in fruits. J. Agric. Food Chem. 2015, 63, 4005-4019. [CrossRef] [PubMed]

22. Brieskorn, C.H.; Briner, M.; Leiner, U. Untersuchungen fiber die Bedeutung der Ursolsäure für die pftanzliche Kutikula. Arch. Pharm. 1954, 287, 305-309. (In German) [CrossRef]

23. Wasan, D.; Nikolov, A.; Kondiparty, K. The wetting and spreading of nanofluids on solids: Role of the structural disjoining pressure. Curr. Opin. Colloid Interface Sci. 2011, 16, 344-349. [CrossRef]

24. Brochard-Wyart, F.; de Gennes, P.; Hervetc, H. Wetting of stratified solids. Adv. Colloid Interface Sci. 1991, 34, 561-582. [CrossRef]

25. Andrade, R.; Skurtys, O.; Osorio, F. Experimental study of drop impacts and spreading on epicarps: Effect of fluid properties. J. Food Eng. 2012, 109, 430-437. [CrossRef]

26. Liu, D.; Pourrahimi, A.M.; Pallon, L.K.H.; Andersson, R.L.; Hedenqvist, M.S.; Gedde, U.W.; Olsson, R.T. Morphology and properties of silica-based coatings with different functionalities for $\mathrm{Fe}_{3} \mathrm{O}_{4}, \mathrm{ZnO}$ and $\mathrm{Al}_{2} \mathrm{O}_{3}$ nanoparticles. RSC Adv. 2015, 5, 48094-48103. [CrossRef]

27. Pourrahimi, A.M.; Olsson, R.T.; Hedenqvist, M.S. The role of interfaces in Polyethylene/Metal-Oxide nanocomposites for ultrahigh-voltage insulating material. Adv. Mater. 2017, 1703624. [CrossRef] [PubMed]

28. Xie, X. A review of recent advances in surface defect detection using texture analysis techniques. Electron. Lett. Comput. Vis. Image Anal. 2008, 7, 1-22.

(C) 2017 by the authors. Licensee MDPI, Basel, Switzerland. This article is an open access article distributed under the terms and conditions of the Creative Commons Attribution (CC BY) license (http:/ / creativecommons.org/licenses/by/4.0/). 